\title{
THE USE OF SUB-TENON BLOCK AS PREEMPTIVE ANALGESIA TO IMPROVE PERIOPERATIV ADVERSE EFFECTS FOR RETINAL DETACHMENT SURGERY
}

\author{
By \\ Salwa MS Hayes*; Mohamed AA Gad**; Amr M Elkannishy** \\ Mohammed Mamdouh** AND Emad Elhefnawy. *
}

\begin{abstract}
From
Department Of Anaesthiology and ICU, Mansoura University, faculty Of Medicine, Mansoura University Hospital, Egypt. Department of Ophthalmology, faculty Of Medicine, Mansoura University, Ophthalmology Center, Egypt.
\end{abstract}

\begin{abstract}
Background and objectives : To study the efficacy of sub-Tenon block in reducing the intensity of pain and reduction of perioperative adverse effects that Occur during retinal detachment repair surgery under general anesthesia.

Materials and methods : Sixty, 60 ASA physical status I or II patients undergoing retinal detachment repair surgery were randomized into two groups, both groups received general anesthesia either with sub-Tenon block(using $2 \mathrm{ml}$ lidocain $2 \%$ and $2 \mathrm{ml}$ bupivacaine $0.5 \%$ ) in the case group
\end{abstract}

or without sub-tenon block in the control group. Intraoperative hemodynamic changes, intraoperative complications and ocular tension monitoring were recorded. Postoperative intensity of pain were assessed by visual analogous score (VAS). Also, occurrence of postoperative nausea and vomiting (PONV) were recorded.

Result : As regard post operative pain, in group 1 (with sub-Tenon injection)early in the recovery, visual analogous score was less than in group 2(without sub-Tenon injection), also the proportion of patient with no

MANSOURA MEDICAL JOURNAL 
pain was higher in group 1 vs group $2(56.7 \%$ vs $36.7 \%)$. visual analogous score at 3 hours post operative was lower in group 1 vs group 2 and the proportion of patient with no pain was more $(53.3 \%$ in group 1 vs $23.3 \%$ group 2). Occurrence of oculocardiac reflex was less in group 1 than in group $2(30.0 \%$ vs $60.0 \%)$, also occurrence of postoperative nausea and vomiting in early post operative period was less in the group 1 than the group 2 (30.0 vs $60.0)$.

Conclusion : The use of subTenon block as a preemptive analgesia for retinal detachment repair surgery may be safe and effective in reducing the intensity of pain in the early post operative period .Decrease the incidence of oculocardiac reflex and postoperative nausea and vomiting is another important benefit.

\section{INTRODUCTION}

Postoperative pain is one of the major problems in the surgical services(Akkaya and Ozkan). Previous study from (Henzler et al) in patient underwent various eye surgeries Vol. 40, No. 1 \& 2 Jan., \& April, 2009 showed that posterior segment surgery was more painful compared to the anterior segment.

Efficacy of preoperative ocular nerve block on pain severity and complications that occur intra and post operatively are frequently encountered by the anesthesiologist. One recommendation to reduce postoperative pain is using preemptive analgesia (Kelly et al) which defined as antinociceptive treatment that prevents establishment of altered central processing of afferent in put from sites of injury .Drugs that stabilize the membrane (e.g local anesthesia) can prevent the formation of action potential of the pain pathway (Kelly et al).

Previous studies showed that the efficacy and safety of a sub-Tenon's approach to local anesthesia in the anterior segment. Several investigators have demonstrated that the subTenon's capsule block can provide safe and effective local anesthesia for vitreoretinal procedures (Patton et al). However, the efficacy of a subTenon's capsule injection in posterior segment surgery is less well established. 
Sub-Tenon's anesthesia acts on the short ciliary nerve, and causes sensory and motor blocks by directly operating on the extraocular muscles' oculomotor nerves (Kumar).

Clinical studies have been performed to know the efficacy of using local anesthetic agents in retinal detachment repair surgery. In one study after ocular nerve block, the incidence of intraoperative oculocardiac reflex, postoperative nausea and vomiting and doses of analgesia given during 24hours, postoperatively were all decreased (Mahfouz and $\mathrm{Na}$ bawi) .

Novel study from (Barakat) and (Lai et al) did not show any benefit of local anesthesia in vitroretinal surgery.

According to previous studies, the effectiveness of preoperative ocular nerve block on pain severity and complications is infrequently studied and the reliability of nerve block is controversial.

This study evaluates the efficacy of preoperative sub-Tenon block us- ing a combination of lidocain and bupivacaine as preemptive analgesia in the repair of retinal detachment .

\section{MATERIALS}

After getting informed consent and ethical committee approval, sixty patients were scheduled for elective repair of retinal detachment surgery under general anesthesia The patients had physical status I or II of ASA classification.

Inclusion criteria were, patients underwent retinal detachment repair with scleral buckling ,age above 18 years old, there were no history of anaphylaxis with local anesthetic and patients were willing to participate in the study. Exclusion criteria were verbal or visual disturbance to VAS interpretation, patient's undertaken beta-blockers and patients with history of postoperative nausea and vomiting after previous anesthesia.

Patients were prospectively randomly divided into two groups (30 patients in each group), randomization were done using the closed enve-

MANSOURA MEDICAL JOURNAL 
lope method, the envelope opened by

a nurse not engaged in the study . Both group received general anesthesia. One group (group 1) received the combination of $(2 \mathrm{ml}$ of $2 \%$ lidocain and $2 \mathrm{ml}$ of $0.5 \%$ bupivacain)through sub-Tenon injection before the start of general anesthesia.

Basal values of systolic blood pressure, diastolic blood pressure, oxygen saturation were recorded preoperatively.

Administration of sub-Tenon local injection was conducted by the ophthalmologist through initially creating incision of the conjunctiva and Tenon capsule along the $2 \mathrm{~mm}$ length starting approximately $6 \mathrm{~mm}$ from the limbus in the inferotemporal quadrant ,blunt cannula was inserted into the retrobulbar space and local anesthetic was injected.The other group (group 2) receive only general anesthesia, both group received general anesthesia with similar method .Induction was done after preoxygenation (with 10 liter flow for $2 \mathrm{~min}$ with (spo2>95\%). Intravenous fentanyl $1 \mu \mathrm{g} / \mathrm{kg}$, thiopental $5 \mathrm{mg} / \mathrm{kg}$ and tra- cheal intubation was facilitated by using atracurium $0.5 \mathrm{mg} / \mathrm{kg}$ Anesthesia was maintained with $\mathrm{O} 2$ only and isoflurane with inspiratory concentration of $1.2 \%$, evaluation of patients was done intraoperatively considering blood pressure (systolic and diastolic blood pressure), heart rate (each 10 minute up to the end of surgery, during the recovery room and in the ward) and occurrence of Oculocardiac Reflex(it was defined as $20 \%$ decrease in the heart rate due to muscle - twitch of ocular muscle).

Postoperative monitoring of the severity of ocular pain according to visual analogous scale (VAS), mild pain with VAS $=0-3$,moderate pain with VAS $=4-7$ and severe pain with VAS $=8-10$.

Postoperative complications such as postoperative nausea and vomiting (PONV) and E.C.G changes were recorded. Also postoperative analgesic (in the form of nonsteroidal anti-inflammatory agent ) requirement by the patient were recorded No prophylactic antiemetic or antimuscarinic agents were given. 


\section{STATISTICAL ANALYSIS}

The statistical analysis of data done by using excel program and statistical package for social science version 10 (SPSS). To test the normality of data distribution Kolmogorov-Smirnov (K-S) test was done only significant data revealed to be nonparametric.

All tested data revealed to be parametric. The description of the data done in form of mean (+/-) SD for quantitative data.

The analysis of the data was done to test statistical significant difference between groups. For quantitative data student t-test was used to compare between two groups. Paired sample ttest to compare one group at different time. Chi square test was used for qualitative data.

$\mathrm{P}$ is significant if $<$ or $=0.05$ at confidence interval $95 \%$.

\section{RESULTS}

Data were obtained from 60 patients ( 40 male \& 20 female) aged from(20-78 years) who underwent retinal detachment repair surgery with scleral buckle. Both groups underwent the same perioperative procedure, except the subtenon injection before general anesthesia in group 1. The duration of surgical procedure was not statistically significant. The average ocular tension after subtenon injection of local anesthetic was slightly higher in group 1 but it was of no importance (table 1).

Perioperative hemodynamic changes (systolic blood pressure, diastolic blood pressure and heart rate) were not statistically significant (table 2).

Intraoperative monitoring of oxygen saturation and end -tidal $\mathrm{CO} 2$ were not statistically significant .

Proportion of patients who were pain -free at recovery between group 1 and group 2 showed $(56.7 \%$ vs $36.7 \%$ ), also 3 hours postoperative $(53.3 \%$ vs $23.3 \%)$. VAS was significantly lower in group 1 vs group 2) both at recovery and $3 \mathrm{~h}$ postoperative, two patients in group 1 vs seven patients in group 2 who need additional analgesia (table 3).

Statistical analysis of severity of pain at $6 h, 12 h, 24 h$, postoperative MANSOURA MEDICAL JOURNAL 
showed that there were no significant

difference between both groups (table vs $60.0 \%$ ) (table 4 ) .

3).

Statistical analysis of occurrence of perioperative complications showed that there were significant differences between group 1 and group 2 as regard the proportion of occur-
Also postoperative nausea and vomiting at recovery showed that the proportion of cases with PONV in the group 1 were less than that of the group $2(30.0 \%$ vs $60.0 \%)$ (table 4).

TABLE (1) : Demographic characteristic Data

\begin{tabular}{|c|c|c|c|}
\hline Variable & $\begin{array}{c}\text { Group 1 } \\
\mathrm{N}=30))\end{array}$ & $\begin{array}{c}\text { Group 2 } \\
\mathrm{N}=30))\end{array}$ & p-value \\
Male & $21(70.0 \%)$ & $19(63.3 \%)$ & 0.58 \\
\hline Female & $9(30.0 \%)$ & $11(36.7 \%)$ & 0.23 \\
\hline $\begin{array}{c}\text { Age(year) } \\
\text { Gender }\end{array}$ & $40 \sim 65$ & $38 \sim 60$ & 0.30 \\
\hline $\begin{array}{c}\text { Duration of } \\
\text { surgery } \\
\text { In min )) }\end{array}$ & $105.6 \pm 9.8$ & $103.3 \pm 7.5$ & $0.005 *$ \\
\hline $\begin{array}{c}\text { Ocular tension } \\
\text { (mmhg)(pre } \\
\text { surgery after } \\
\text { subtenon) }\end{array}$ & $12.0 . \pm .83$ & $11.4 \pm .96$ & \\
\hline
\end{tabular}

Values were given as mean \pm SD except for sex data were presented as relative frequency.

No significant differences

Increase ocular tension in group 1._ 


\begin{tabular}{|c|c|c|c|}
\hline $\begin{array}{l}\text { Haemodynamic } \\
\text { changes }\end{array}$ & $\begin{array}{l}\text { Group } 1 \\
(n=30)\end{array}$ & $\begin{array}{c}\text { Group } 2 \\
(n=30)\end{array}$ & $\mathrm{P}$ - value \\
\hline SBp -basal & $\begin{array}{c}141.6 \pm \\
11.0\end{array}$ & $140.3 \pm 10.0$ & 0.64 \\
\hline $\begin{array}{l}\text { SBP- (every } 10 \mathrm{~min}) \\
\text { intraoperative }\end{array}$ & $121.7 \pm 7.9$ & $115.3 \pm 6.6$ & $0.001 * *$ \\
\hline SBP -recovery & $\begin{array}{l}129.5 \\
\pm 13.3\end{array}$ & $130.7 \pm 8.2$ & 0.68 \\
\hline SBP -ward & $\begin{array}{l}125.3 \\
\pm 12.5\end{array}$ & $122.6 \pm 13.2$ & 0.41 \\
\hline DBP-basal & $92.1 \pm 6.1$ & $89.4 \pm 6.1$ & 0.08 \\
\hline $\begin{array}{l}\text { DBP-(every } 10 \mathrm{~min}) \\
\text { intraoperative }\end{array}$ & $73.04 \pm 8.1$ & $72.3 \pm 10.1$ & 0.778 \\
\hline DBP-recovery & $73.9 \pm 21.1$ & $78.3 \pm 24.1$ & 0.459 \\
\hline DBP-ward & $74.9 \pm 14.9$ & $77.8 \pm 12.9$ & 0.43 \\
\hline HR-basal & $83.1 \pm 12.1$ & $82.9 \pm 12.2$ & 0.95 \\
\hline HR-intraoperative & $85.3 \pm 6.3$ & $84.9 \pm 6.4$ & 0.81 \\
\hline HR-recovery & $99.2 \pm 10.3$ & $98.8 \pm 10.9$ & 0.89 \\
\hline HR-ward & $79.7 \pm 7.1$ & $80.3 \pm 6.1$ & 0.72 \\
\hline
\end{tabular}

No significant differences between both groups .

Values were given as mean \pm SD .

$\mathrm{SBP}=$ systolic blood pressure(mmhg) .

$\mathrm{DBP}=$ diastolic blood pressure(mmhg) .

$\mathrm{HR}=$ heart $\mathrm{rate}($ beat $/ \mathrm{min})$. 
204 THE USE OF SUB-TENON BLOCK AS PREEMPTIVE etc..

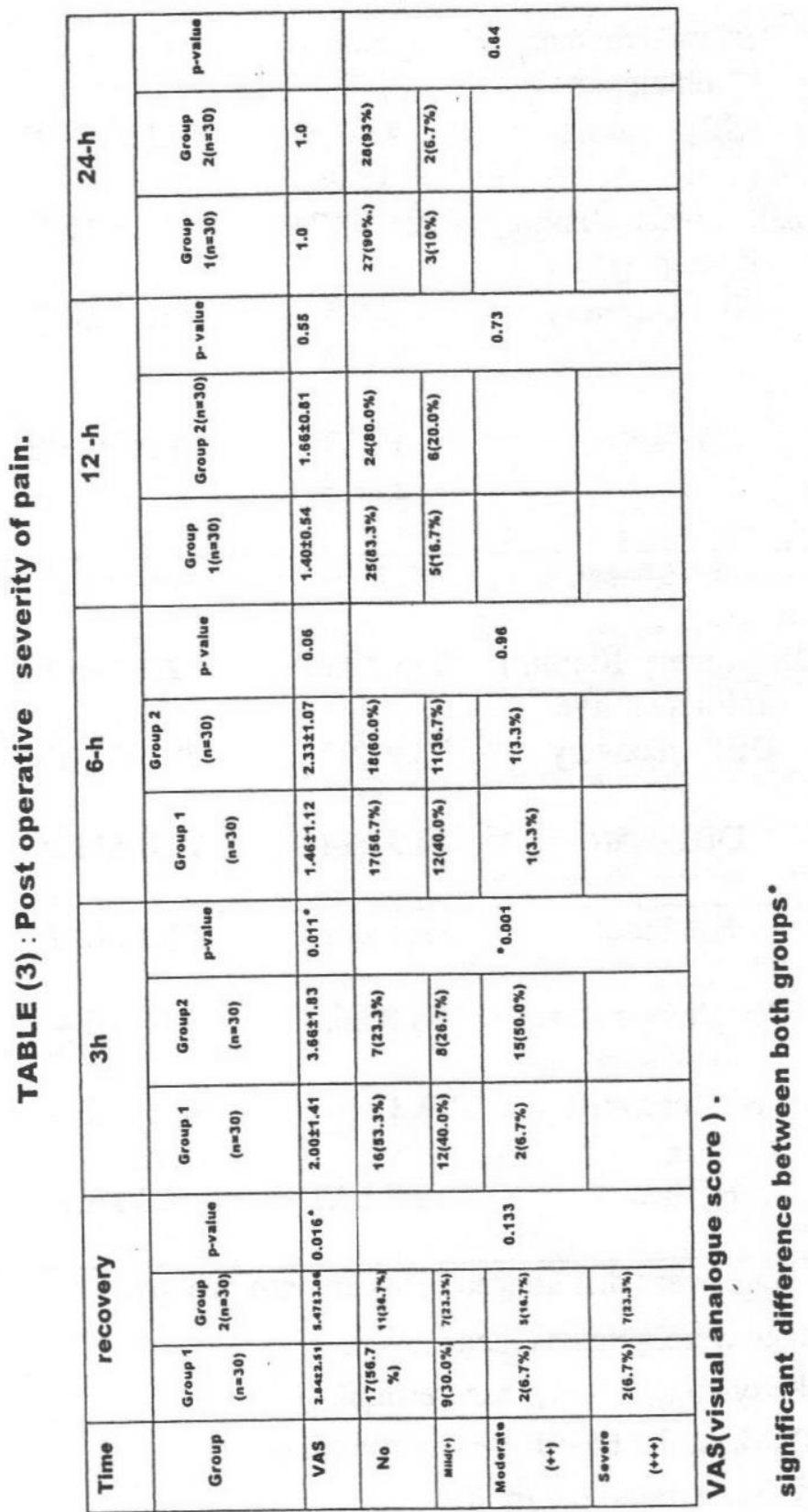

Vol. 40, No. 1 \& 2 Jan., \& April, 2009 
TABLE (4) : Perioperative complications.

\begin{tabular}{|c|c|c|c|}
\hline variable & $\begin{array}{c}\text { Group1 } \\
(\mathbf{n}=30)\end{array}$ & $\begin{array}{c}\text { Group 2 } \\
\mathbf{N}=30))\end{array}$ & P- value \\
\hline OCR & $9(30.0 \%)$ & $18(60.0 \%)$ & $0.020 *$ \\
\hline PONV- recovery & $9(30.0 \%)$ & $18(60.0 \%)$ & $0.020^{*}$ \\
\hline PONV-ward & $5(16.7 \%)$ & $10(33.3 \%)$ & 0.136 \\
\hline $\begin{array}{c}\text { With sleep } \\
\text { disturbance }\end{array}$ & $19(63.3 \%)$ & $18(60.0 \%)$ & 0.893 \\
\hline
\end{tabular}

PONV=post operative nausea and vomiting.

Data are presented as relative frequency.

* significant reduction of proportion of patient without occurrence of OCR and $\mathrm{PONV}$ in the case group. 


\section{DISCUSSION}

This study showed that the proportion of patient with no pain in group 1 was more than that of group $2(56.7 \%$ vs $36.7 \%)$ at the recovery period, and also 3hours post operative $(53.3 \%$ vs $23.3 \%)$ this may indicate the success of analgesic effect of local subtenon in group 1

According to (Safavi et al), study the incidences of post operative ocular severity of pain, up to 24 hours, were significantly lower in the case group compared with the control group.

(Afifudin et al), showed that the mean VAS and the proportion of pain free patients between the two groups were similar .

(Kristin et al), showed that the average value of VAS in the case group was 1.00 while that of the control group was 3.00 , their study showed that the proportion of pain free patients was $65 \% \quad 3$ hours postoperative . Similar research by (Clarke et al), showed that a number of success range between $(56 \%$ $72 \%$ cases), while proportion of Vol. 40, No. 1 \& 2 Jan., \& April, 2009 patients who were pain free in both groups were similar $(65 \%$ vs $65 \%)$.

Systemic study from (Ong et al), showed that the results for preemptive analgesia in many cases were still variable. (Mason et al), showed that the addition of local block did not affect the measurement of pain incidence, also (Bahcecioqlu et al), showed that the local anesthesia did not provide additional benefits in the vitroretinal operation. some authors have observed that preemptive anesthesia with preoperative nerve block is insufficient this may be due to, less adequate afferent block, pain intensity and type of operation, inflammatory mediators and the individual reaction post-operative.

Controversial result was obtained from (Guise), who showed that the sub-Tenon block was very effective.

(Calenda et al), showed that the average VAS in sub-Tenon group was lower than that of the control group.

The result of this revealed that 
sub -Tenon block decrease the PONV during the recovery and later in the ward also significant reduction of the occurrence of intraoperative OCR which was very useful result in this research, also there was decrease postoperative analgesia given in group 1.

Similar research by (Safavi et al) which revealed that sub-Tenor, block reduced $P O N V$ and occurrence of intraoperative OCR.

As a whole, according to this study, sub-Tenon block as a preemptive analgesia for retinal detachment repair surgery was safe and effective in reducing pain intensity at early post operative period and also decrease the incidence of intraoperative complication and postoperative nausea and vomiting .

\section{CONCLUSION}

1-This study showed that sub-Tenon block reduce the intensity of ocular pain in retinal detachment repair surgery

2-Reduction of PONV during recovery.

3-In addition, reducing the incidence of occurrence of intraoperative OCR is another usefulness of this block

\section{REFERENCES}

1. Afifudin M, Hartono, Angela Nurini Agni (2009) : The efficacy of the combination of $2 \%$ lidocaine and $0.5 \%$ bupivacaine as preemptive analgesia for post-operative painin vitrectomy with or without scleral buckle under general anaesthesia. Berkala IImAuf Kifeudoink teetr aln 2009 ; Vol. 41, No. 2, Juni : 89-95.

2. Akkaya T, Ozkan A. (2009) : Chronic post surgical pain. AGRI; 21(1):1-9.

3. Bahcecioqlu H, Unal M, Artunay O, Rasier R, Sarici A. (2007) : Posterior Vitrectomy Under Topical Anesthesia. Can J Ophthalmol;42 (2):272-77.

4. Barakat SS. (2004) : Modified subtenon.s parabulbar anesthesia for vitreoretinal surgery. MANSOURA MEDICAL JOURNAL 
Eng J Anesthesia;20:18588.

\section{Calenda E, Quyntin JC, Brasseur} G. (2002) : Peribulbar anaesthesia using a combination of lidocaine, bupivacaine and clonidine in vitreoretinal surgery. Indian J Ophthalmol; 50(3):205-08.

6. Clarke JP, Roberton G, Plummer J. (2006) : Sub-tenon block: alearning curve of 100 cases. Anaesth Intensive Care; 34(4): 450-52.

7. Guise PA. (2003) : Sub-Tenon Anesthesia: A Prospective Study of 6000 blocks. Anaesthesiology.; 98(4):96468.

8. Henzler D, Kramer R, Steinhorst UR, Piepenbrock R, Rossaint R. (2004) : Factors independently associated with increased risk of pain after ophthalmic surgery. Eur J Anesth; 21:101-06.

9. Kelly DJ, Ahmad M, Brull SJ.
(2001) : Preemptive analgesia: physiological pathways and pharmacological modalities. Can J Anesth; NOV, 48(10):1000-10.

10. Kristin N, Schoenfeld C, Bechmann $M$, Bengsiu M,Ludwig K, Cheider Am Kampik A. (2001) : Vitreoretinal surgery:pre-emptive analgesia. $\mathrm{Br} \mathrm{J}$ Ophthalmol; 85:1328-31.

11. Kumar CM. (2005) : Ophthalmic regional anesthesia: a review of techniques. Egypt $\mathrm{J}$ Anaesth ; 21:183-190.

12. Lai MM, Lai, JC, Lee WH, Huang JJ. (2005) : Comparison of retrobulbar and sub-tenon.s capsule injection of local anesthetic in vitreoretinal surgery. Ophthalmology; 112: 574-79.

13. Mahfouz AK, Nabawi KS. (2002) : Preemptive analgesia in rhegmatogenous retinal detachment surgery: is it effective? Retina.: Oct; 22:602-606. 
Salwa MS Hayes et al ..

14. Mason JO, Goodwin PL, Feist RM, Vail RS. (2007) : Preemptive Sub-Tenon Anesthesia for Pars Plana Vitrectomy Under General Anesthesia: Is It Effective? Opthalmic Surg Laser Imaging; 38(3): 203-08.

15. Ong CKS, Lirk $P$, Seymour RA, Jenkins BJ. (2005) : The efficacy of preemptive analgesia for acute postoperative pain management: a meta-analysis.

Anesth Analg; 100: 757-73.

16. Patton N, Malik TY, Aslam TM, Vallance JH. (2004) : Ef- fect of volume used in subTenon's anesthesia on efficacy and intraocular pressure: a randomized clinical trial of $3 \mathrm{ml}$ versus $5 \mathrm{ml}$. Clin Experiment Ophthalmol; 32:488-491 .

17. Safavi MR, Aghadavoudi $O$, Soltani H, Hashemi S,D ehghani A,Mahjobi $H$, Loghmanian L. (2005) : Preoperative sub-tenon block decreases perioperative pain severity and adverse complications . Medical Journal Of Islamic World Academy Of Sciences .; 15; 1, 13- 17 
